\title{
On the Effect of Treating Poly (acrylic acid) with Argon and Tetrafluoromethane Plasmas: Kinetics and Degradation Mechanism
}

\author{
JOHANNES G. A. TERLINGEN, ' GIJSBERT A. J. TAKeNS,' FREDERIK J. VAN DER GAAG,' \\ ALLAN S. HOFFMAN, ${ }^{2}$ and JAN FEIJEN * \\ 'Department of Chemical Technology, University of Twente, P.O. Box 217, 7500 AE Enschede, The Netherlands; \\ ${ }^{2} \mathrm{Ctr}$. for Bioengineering $\mathrm{Fl}-20$, University of Washington, Seattle, Washington 98195
}

\begin{abstract}
SYNOPSIS
Poly (acrylic acid) (PAAc) films were treated with either an argon or a tetrafluoromethane $\left(\mathrm{CF}_{4}\right.$ ) plasma and subsequently analyzed with $\mathrm{X}$-ray photoelectron spectroscopy (XPS). PAAc films were decarboxylated during both types of plasma treatments. In addition, during the $\mathrm{CF}_{4}$ plasma treatment, the PAAc films became fluorinated. The plasma phase during the argon plasma treatment of PAAc films was investigated with optical emission spectroscopy. It was shown that during this plasma treatment carbon dioxide, water, and possibly hydrogen were liberated from the PAAc surface. By covering the surface of PAAc films with different materials (lithium fluoride, UV fused silica, and glass) during the plasma treatment, it was possible to differentiate between photochemically induced and particleinduced changes of the surface. This method was used to show that decarboxylation during the argon plasma treatment was caused by vacuum UV radiation (wavelength $<150 \mathrm{~nm}$ ) and the decarboxylation/fluorination during the $\mathrm{CF}_{4}$ plasma treatment was induced by reactive fluorine-containing species from the plasma phase. Furthermore, during both processes, etching of the PAAc surface occurred. Based on these mechanisms, kinetic models were derived that could be used to describe the measured kinetic data adequately. (c) 1994 John Wiley \& Sons, Inc.
\end{abstract}

\section{INTRODUCTION}

Plasma techniques have been widely used for the introduction of functional groups on polymer surfaces. ${ }^{1}$ Although several groups like hydroxyl groups are readily formed by treating a polymer surface with a water plasma, ${ }^{2}$ the selective introduction of carboxylic acid groups by, e.g., plasma polymerization of acrylic acid is difficult. ${ }^{3-5}$ When a polymer is treated with an oxidative plasma, a wide spectrum of oxygen-containing functional groups is introduced at the surface. ${ }^{6-9}$ To specifically obtain carboxylic acid groups on polymer surfaces, other strategies like plasma-induced grafting ${ }^{10,11}$ or grafting of preadsorbed carboxylic acid group containing monomers like acrylic acid have been successfully applied. ${ }^{12}$

* To whom correspondence should be addressed. Journal of Applied Polymer Science, Vol. 52, 39-53 (1994)

(C) 1994 John Wiley \& Sons, Inc. CCC 0021-8995/94/010039-15
To create carboxylic acid groups on a polyethylene (PE) surface that can be used for the covalent coupling of bioactive molecules, we tried to immobilize preadsorbed layers of poly (acrylic acid) (PAAc) on PE by applying an argon or tetrafluoromethane $\left(\mathrm{CF}_{4}\right)$ plasma treatment. ${ }^{13}$ Although the concept of immobilizing a preadsorbed layer on polymer surfaces by using a plasma treatment has been successfully used for the introduction of sulfate ${ }^{14}$ and amine ${ }^{15}$ groups at hydrophobic polymers, the immobilization of PAAc layers on PE was not successful. The preadsorbed PAAc was etched more rapidly than it became immobilized on the surface. From the gravimetrically determined etching rates, it was concluded that PAAc is much more sensitive to argon and $\mathrm{CF}_{4}$ plasmas as compared to $\mathrm{PE} .^{13}$

Clark and Dilks showed that argon plasmas emit substantial amounts of hard UV radiation, with wavelengths starting from $90 \mathrm{~nm} .{ }^{16}$ Several authors 
have shown that this UV radiation induces chemical changes of polymer surfaces during plasma treatments. ${ }^{17-19}$ Because carboxylic acid-containing compounds are known to be sensitive to UV radiation with wavelengths of around $200 \mathrm{~nm},{ }^{20}$ it seems possible that the sensitivity of PAAc to argon and $\mathrm{CF}_{4}$ plasmas is caused by the UV irradiation from the plasma phase. By covering the PAAc films with UV transparent materials during the plasma treatment, the direct-ion/electron and metastable bombardment-and radiative (UV) processes can be discriminated. The materials form a physical barrier for the bombardment of reactive species from the plasma phase, and by selection of materials with different cutoff values, it is possible to test which spectral region of the UV irradiation induces surface damage.

In this study, the effect of an argon or a $\mathrm{CF}_{4}$ plasma treatment on the chemical composition of PAAc films was investigated. Surface analysis of the modified films was performed by using $X$-ray photoelectron spectroscopy (XPS). The kinetics and the mechanism of plasma-induced surface reactions were studied using covered and noncovered substrates during the plasma treatment. To obtain some additional qualitative information on the degradation of PAAc during plasma treatments, the plasma phase during the treatment of PAAc films was studied with optical emission spectroscopy (OES) ${ }^{21,22}$

\section{MATERIALS AND METHODS}

\section{Materials}

Poly (acrylic acid) (PAAc): Aldrich Chemie, Brussel, Belgium, molecular weight $250,000 \mathrm{~g} / \mathrm{mol}$ (according to the supplier). PE film: low-density poly (ethylene) thickness $0.2 \mathrm{~mm}$, type 2300 , DSM, Geleen, The Netherlands. This PE does not contain additives. Poly (tetrafluoroethylene) (PTFE): thickness $0.5 \mathrm{~mm}$, Good Fellow, Cambridge, England. Methanol, dichloromethane, and acetone: Merck, Darmstadt, Germany (purity > 99.5\%). Water: doubly deionized water. UV fused silica $\left(\mathrm{SiO}_{2}\right)$ : thickness $3.1 \mathrm{~mm}$, transparent for UV with wavelengths longer than $150 \mathrm{~nm}$ (according to the supplier), and vacuum UV lithium fluoride ( $\mathrm{LiF}$ ): thickness $3 \mathrm{~mm}$, transparent to UV with wavelengths longer than $104 \mathrm{~nm}, \mathrm{ABC}$ Diagnostics, Utrecht, The Netherlands. Glass slides: thickness 1 $\mathrm{mm}$, Tamson, Zoetermeer, The Netherlands. Argon (purity $\geq 99.999 \%)$, tetrafluoromethane $\left(\mathrm{CF}_{4}\right)$ (purity $\geq 99.95 \%$ ), carbon dioxide $\left(\mathrm{CO}_{2}\right)$ (purity $\geq 99.995 \%$ ): Hoekloos, Amsterdam, The Netherlands.

\section{Methods}

All films before and after modification were stored in glass vials in the dark at ambient conditions.

\section{Preparation of PAAC Films}

PAAc ( $10 \mathrm{~g}$ ) was dissolved in $500 \mathrm{~mL}$ of methanol. The solution was then cast onto two clean Petri dishes (diameter $19 \mathrm{~cm}$ ). After evaporation of the methanol, the PAAc films were dried in vacuo at room temperature (RT).

\section{Cleaning of PE and PTFE Films}

PE and PTFE films were cleaned ultrasonically in dichloromethane for $10 \mathrm{~min}$. The dichloromethane was refreshed and the procedure was repeated. The total cleaning procedure consisted of four times treatment with dichloromethane, four times with acetone, and four times with water. Subsequently, the films were dried in vacuo at RT and stored.

\section{Plasma Treatment}

An extensive description of the plasma treatment system has been given previously. ${ }^{13}$ In brief, the plasma system consists of a tubular reactor (internal diameter $6.5 \mathrm{~cm}$ ) with three externally placed capacitively coupled electrodes spaced at $10 \mathrm{~cm}$ distances. One side of the tubular reactor was connected to a turbomolecular and to a two-stage rotary vane pump. The other side was attached to a gas inlet controlled by mass flow controllers. The electrodes were powered through a matching network by a 13.56 $\mathrm{MHz}$ radio-frequency generator, which was controlled by a timer (function generator). This system enables an optimal control of the plasma treatment time.

A PAAc film $(3 \times 3 \mathrm{~cm})$ was placed in the center region of the reactor on a glass plate and the reactor was evacuated (pressure $<1 \times 10^{-5} \mathrm{mbar}$ ). Subsequently, a gas flow ( $\mathrm{Ar}$ or $\mathrm{CF}_{4}$ ) of $10 \mathrm{~cm}^{3} / \mathrm{min}$ was established through the reactor. After $15 \mathrm{~min}$, the films were plasma-treated ( $44 \mathrm{~W}, 0.07 \mathrm{mbar}$ ) for different time periods ranging from 0.05 to $1000 \mathrm{~s}$. Two minutes after the plasma treatment, the reactor was brought to atmospheric pressure with air and the films were taken out.

To test whether UV radiation from the plasma phase induces changes of the chemical composition of the surface, PAAc films covered with a $\mathrm{SiO}_{2}$ crys- 
tal, a LiF crystal, or glass were plasma-treated. Because the PAAc films were not completely flat, usually a small gap ( $\leq 2 \mathrm{~mm}$ ) between the PAAc surface and the covering material existed. The plasma treatment procedure used was similar to the procedure described above. It should be noted that $\mathrm{LiF}$ crystals are severely damaged by an argon plasma treatment. The transparency of the crystal for UV decreases significantly even after short plasma treatment times. To minimize this effect, a new crystal was used for every experiment.

To determine whether the covering of the substrate with the different materials was sufficient to prevent the interaction of species from the plasma phase with covered surfaces, the spacing between two glass plates was varied (from direct contact to $4 \mathrm{~mm}$ ). The PAAc film to be treated was placed in between these glass plates. The films were plasmatreated for $1000 \mathrm{~s}$ according to the procedure described previously. At separations smaller than 5 $\mathrm{mm}$, no plasma developed in between the glass plates.

\section{Characterization}

\section{X-ray Photoelectron Spectroscopy (XPS) Measurements}

XPS measurements were performed with a Kratos XSAM-800 (Manchester, UK) apparatus using a $\mathrm{MgK} \alpha$ source ( $15 \mathrm{kV}, 15 \mathrm{~mA}$ ). The analyzer was placed perpendicular to the sample surface for routine analysis. During angle-dependent XPS measurements (AD-XPS), the angle between the surface and the analyzer was varied between $0^{\circ}$ (perpendicular) and $75^{\circ}$. A spot size with a diameter of $3 \mathrm{~mm}$ was analyzed. The spectra were recorded in the low-resolution mode (pass energy $40 \mathrm{eV}$, fwhm Ag3 $d^{5 / 2}: 1.2 \mathrm{eV}$ ) and standard sensitivity factors (delivered by Kratos ) were used to convert the measured peak areas into atom percentages. To determine a correct empirical sensitivity factor for the F1s peak, a clean PTFE sample was analyzed whenever fluorine-containing films were analyzed. For PAAc and modified PAAc films, short analysis times should be used, because significant radiation damage occurs during the XPS measurements at prolonged times.

Peak fitting of the C1s spectra was performed by fitting the spectra of argon plasma-treated and untreated PAAc films with three Gaussian peaks. A hydrocarbon peak at $284.6 \mathrm{eV}$, a $\mathrm{C}-\mathrm{O}$ peak at 286.1 $\mathrm{eV}$, and a carboxylic acid peak at $288.6 \mathrm{eV}$ were used. The fraction of carboxylic acid groups on the surface was calculated by dividing the surface area under the carboxylic acid peak by the total area of the $\mathrm{C} 1 \mathrm{~s}$ peak.

\section{Optical Emission Spectroscopy (OES)}

OES has been used to analyze the plasma phase during the plasma treatment of PAAc and PE. Similar conditions (except for a much larger film area of $90 \mathrm{~cm}^{2}$ ) as described for the plasma treatment of PAAc were used. To increase the concentration of degradation products, a different set of discharge conditions were used: $44 \mathrm{~W}, 0.24 \mathrm{mbar}$, and $3.0 \mathrm{sccm} /$ min argon. For comparison, also spectra of argon/ water and of $\mathrm{Ar} / \mathrm{CO}_{2}$ mixtures were recorded. The water was repeatedly (three times) frozen, degassed to $0.01 \mathrm{mbar}$, and thawed before use. The flow rates of the very small amounts of water or $\mathrm{CO}_{2}(0.3 \mathrm{sccm} /$ $\mathrm{min}$ ) were determined from the increase rate of the pressure in the reactor and were controlled by needle valves. A quartz window at the vacuum side of the reactor and a spectroradiometer SR 9010-PC (Macam Photometrics, Livingston, Scotland) were used

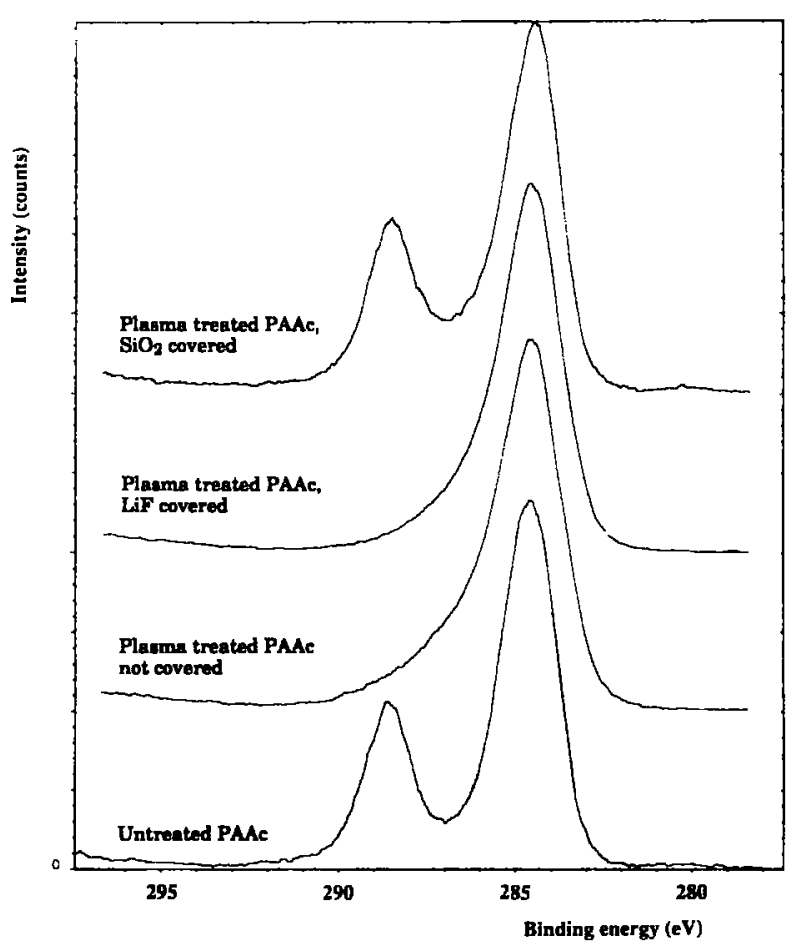

Figure 1 XPS spectra of the C1s region of argon plasma-treated (treatment time $500 \mathrm{~s}$ ) PAAc films. The spectra of untreated and of argon plasma-treated films, which were either covered (with UV fused silica $\left(\mathrm{SiO}_{2}\right)$ or lithium fluoride ( $\mathrm{LiF})$ ) during the plasma treatment or not covered, are shown. 
to record emission spectra (from 240 to $800 \mathrm{~nm}$ with a step width of $2 \mathrm{~nm}$ ).

\section{RESULTS}

\section{Argon Plasma Treatment of PAAc}

In Figure 1, the XPS spectra of the C1s region of argon plasma-treated PAAc films are shown. The peak at $288.6 \mathrm{eV}$, which is due to the pendant carboxylic acid groups of the PAAc, is lacking in the $\mathrm{C} 1 s$ spectrum of the argon plasma-treated $(500 \mathrm{~s})$ PAAc films. Also, in the spectrum of LiF-covered argon plasma-treated PAAc films, the peak at 288.6 $\mathrm{eV}$ is lost. For PAAc films covered with a $\mathrm{SiO}_{2}$ crystal or glass during the plasma treatment, no change in the $\mathrm{C} 1 s$ spectrum compared to untreated PAAc films is observed.

In Figure 2, the oxygen-to-carbon $(\mathrm{O} / \mathrm{C})$ ratios of argon plasma-treated PAAc films are given as a function of the plasma treatment time. After a plasma treatment time of $1 \mathrm{~s}$, the plasma induces an oxygen loss at the surface, which increases with increasing plasma treatment time. At $50 \mathrm{~s}$, the $O /$ $\mathrm{C}$ ratio levels off to a plateau level of around 0.18. Treating the PAAc films for longer time periods does not induce further changes in the surface chemistry according to the XPS measurements. The results for PAAc films that are covered with materials during the plasma treatment are also given in Figure 2.
Only LiF-covered PAAc films show a significant decrease in the $\mathrm{O} / \mathrm{C}$ ratio with increasing plasma treatment time. At a plasma treatment time of 500 $s$, the $\mathrm{O} / \mathrm{C}$ ratio decreases to a level lower than that of uncovered PAAc films that were plasma-treated for a similar time period.

Because the pendant carboxylic acid groups in PAAc give a distinct peak (at $288.6 \mathrm{eV}$ ) in the $\mathrm{C} 1 s$ spectra, peak fitting of the $\mathrm{C} 1 s$ spectra of argon plasma-treated PAAc films yields information on the chemical changes induced on the surface by the plasma treatment. In Figure 3, the fraction of carboxylic acid groups remaining on the surface for uncovered and covered (with different materials) films is given as a function of the argon plasma treatment time. The shape of the curve is similar to that of Figure 2.

To investigate whether the covering of the films is sufficient to totally block the interaction of reactive particles from the plasma phase with the PAAc surface, the distance between two glass plates was varied. In Figure 4, the results of the XPS analysis of argon plasma-treated PAAc films (1000 s), which were placed in between two glass plates during the plasma treatment, are given. It is shown that regardless of the spacing between the glass plates no changes in the surface chemistry are observed with XPS.

The results of the AD-XPS analysis of argon plasma-treated uncovered PAAc films are given in Figure 5. The $\mathrm{O} / \mathrm{C}$ ratio is given as a function of

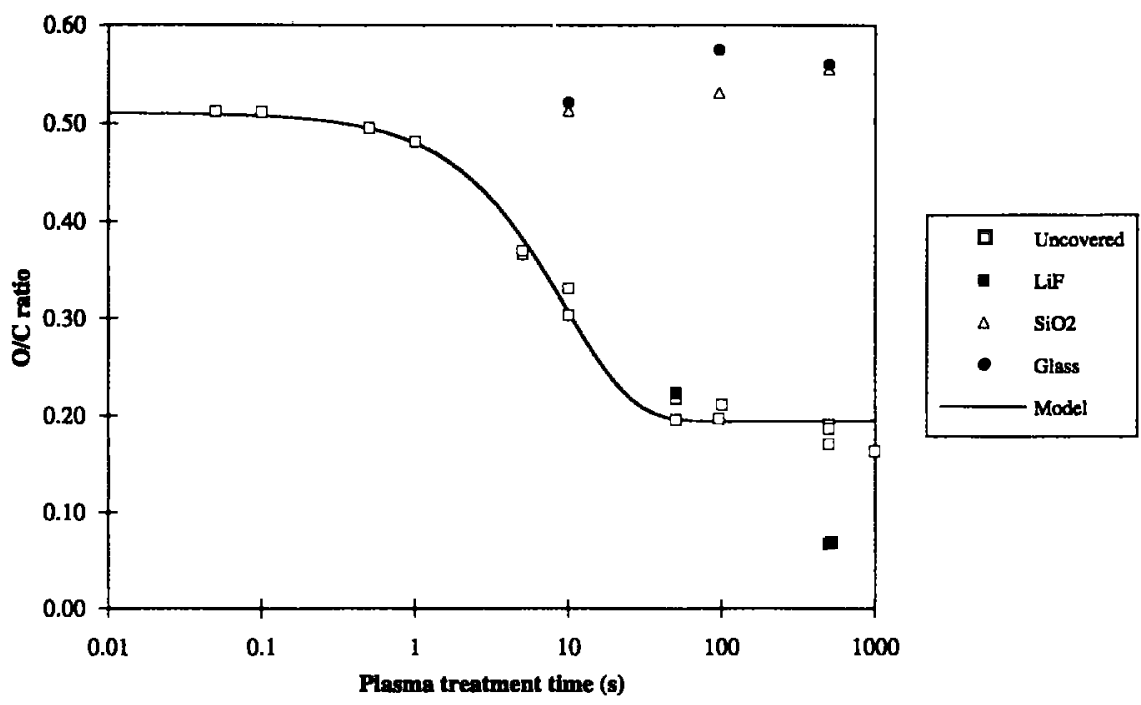

Figure 2 XPS analysis of argon plasma-treated PAAc films. The ratio of oxygen to carbon $(\mathrm{O} / \mathrm{C})$ is given as a function of the applied plasma treatment time. The films were either covered (with glass, $\mathrm{SiO}_{2}$, or $\mathrm{LiF}$ ) during the plasma treatment or not covered. Also, the best fit for eq. (5) is given for plasma-treated (not covered) PAAc films. 


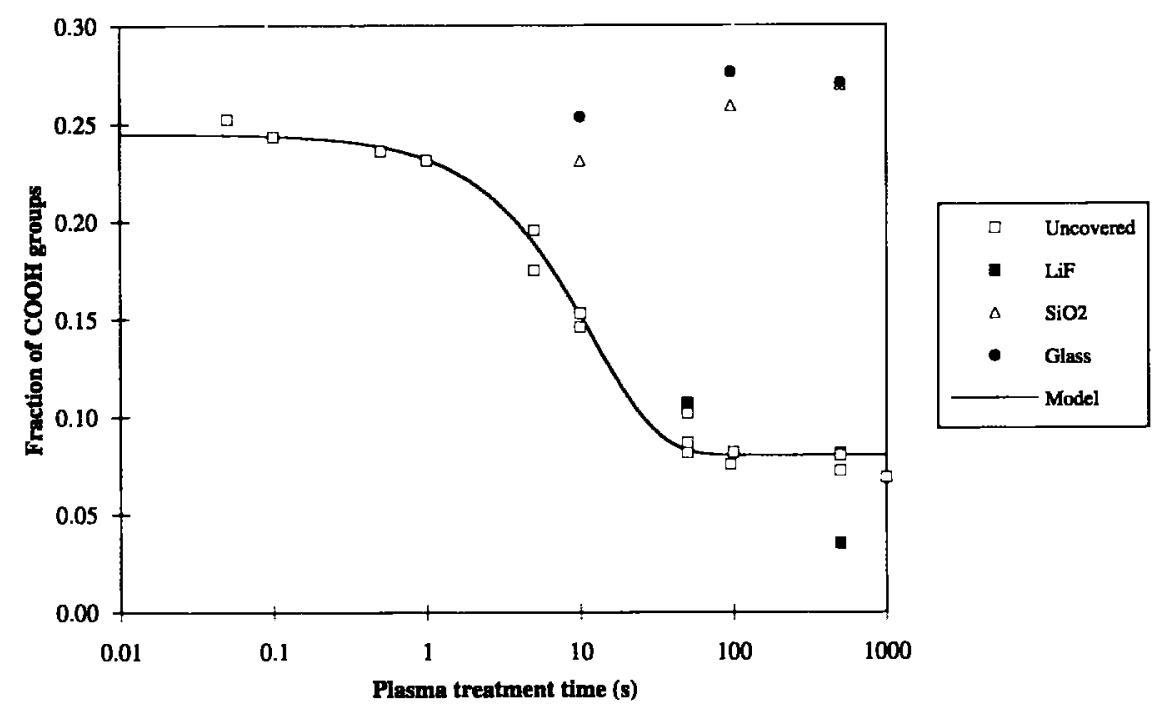

Figure 3 XPS analysis of argon plasma-treated PAAc films. The fraction of carboxylic acid groups left on the surface, which is determined by peak fitting of the C1s spectra, is given as a function of the plasma treatment time. The films were either covered (with glass, $\mathrm{SiO}_{2}$, or $\mathrm{LiF}$ ) during the plasma treatment or not covered. Also, the best fit for eq. (5) is given for plasma-treated (not covered) PAAc films.

the cosine of the take-off angle. At a take-off angle of $0^{\circ}$, a depth of approximately $100 \AA$ is probed. At an angle of $75^{\circ}$, the XPS analysis is more surfacesensitive and the probed depth is in the order of 25 $\AA$. Within the accuracy of the XPS method (approximately $10 \%$ ), the $0 / C$ ratio is not dependent on the probed depth (see Fig. 5).

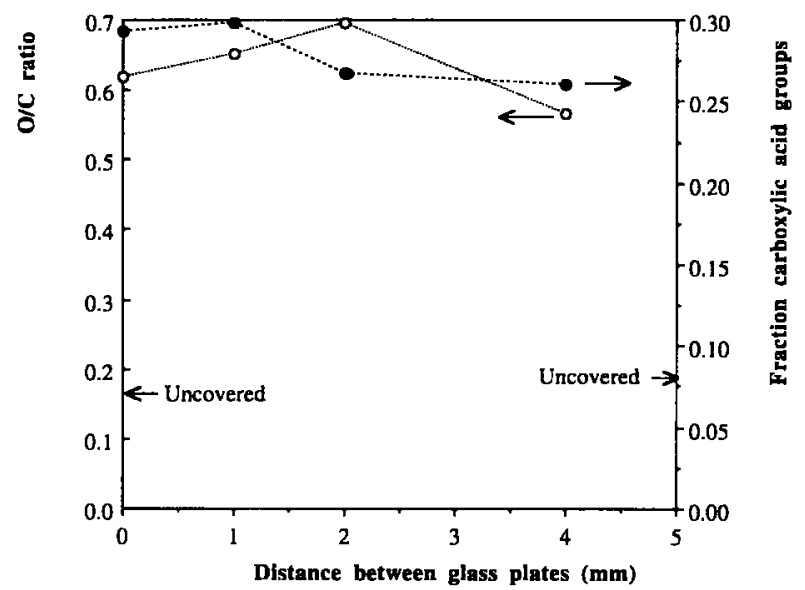

Figure 4 XPS analysis of argon plasma-treated PAAc films $(1000 \mathrm{~s})$, which were placed in between two glass plates during the plasma treatment. The ratio of oxygen to carbon and the fraction of carboxylic acid groups left on the surface are given as a function of the spacing between the glass plates.

\section{$\mathrm{CF}_{4}$ Plasma Treatment of PAAc}

Figure 6 shows the C1s spectra of $\mathrm{CF}_{4}$ plasmatreated ( $1000 \mathrm{~s}$ ) PAAc films. After plasma treatment of uncovered PAAc films, not only hydrocarbon $(\mathrm{C}-\mathrm{H})$ moieties are present but also $\mathrm{CF}, \mathrm{CF}_{2}$, and $\mathrm{CF}_{3}$ groups are formed at the surface. $\mathrm{CF}_{4}$ plasma

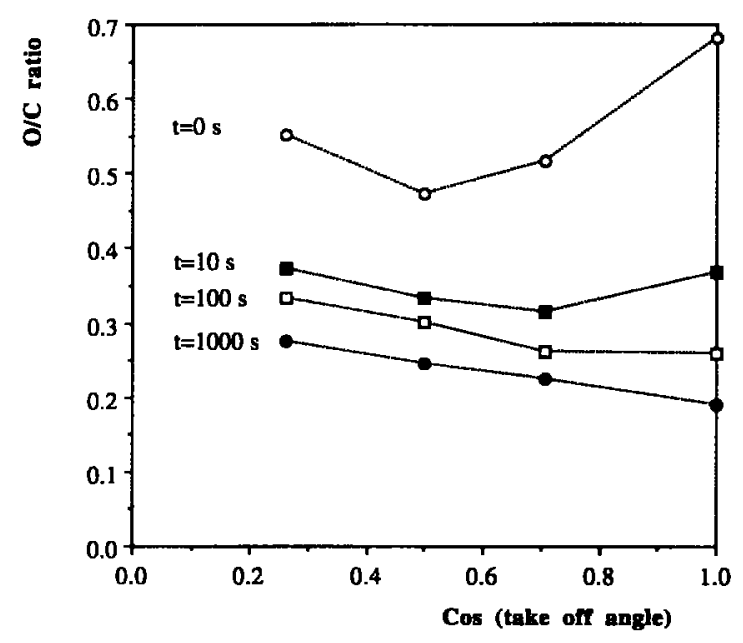

Figure 5 Angle-dependent XPS measurements on argon plasma-treated PAAc films. The ratio of oxygen to carbon is given as a function of the cosine of the take-off angle for films plasma treated for different time periods. At an angle of $0^{\circ}$, the largest depth is probed. 


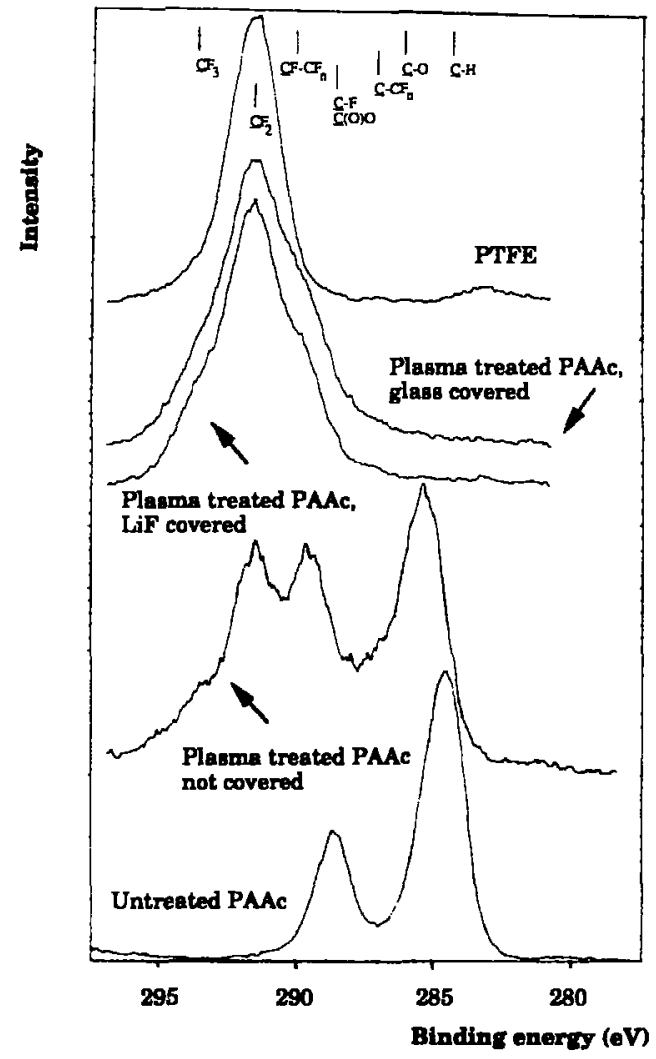

Figure 6 XPS spectra of the $\mathrm{C} 1 s$ region of $\mathrm{CF}_{4}$ plasmatreated (treatment time $1000 \mathrm{~s}$ ) PAAc films. The spectra of untreated and of $\mathrm{CF}_{4}$ plasma-treated films, which were either covered (with LiF or glass) during the plasma treatment or not covered, are given. For comparison, the $\mathrm{C} 1 s$ spectrum of PTFE and the shifts for different fluorine containing groups are given. ${ }^{23}$ The $\underline{\mathrm{C}}-\mathrm{H}$ component of the C1s was set on $284.6 \mathrm{eV}$, and for fluorinated films, the F1s peak was set on $689.2 \mathrm{eV}^{24}$ to correct for charging effects during the XPS measurements.

treatment of PAAc films covered with $\mathrm{LiF}, \mathrm{SiO}_{2}$ (spectrum not given), or glass yields a totally different distribution of fluorine-containing groups. In this case, primarily, $\mathrm{CF}_{2}$ groups and only small amounts of $\mathrm{CF}$ and $\mathrm{CF}_{3}$ groups are found on the surface. It is quite remarkable that there are no hydrocarbon groups present at the surface of these films.

The quantitative results of the XPS analysis of the $\mathrm{CF}_{4}$ plasma-treated PAAc films are given in Figures 7 and 8 . In Figure 7 , the $\mathrm{O} / \mathrm{C}$ ratio, and in Figure 8, the ratio of fluorine to carbon ( $F / C$ ), are given as a function of the plasma treatment time. After a plasma treatment time of approximately 1 $\mathrm{s}$, the $\mathrm{O} / \mathrm{C}$ ratio decreases with increasing plasma treatment time. After $50 \mathrm{~s}$, the $\mathrm{O} / \mathrm{C}$ ratio for uncovered PAAc films levels off. For PAAc films that are covered with different materials during the plasma treatment, the $\mathrm{O} / \mathrm{C}$ ratio decreases beyond the levels found for uncovered PAAc films.

From Figure 8 it can be seen that after a plasma treatment time of $0.1 \mathrm{~s}$ the $\mathrm{F} / \mathrm{C}$ ratio increases with increasing plasma treatment time. Similarly to the $\mathrm{O} / \mathrm{C}$ ratio, the $\mathrm{F} / \mathrm{C}$ ratio levels off after a treatment time of approximately $50 \mathrm{~s}$. For all covered films, an increase in the $\mathrm{F} / \mathrm{C}$ ratio with increasing plasma treatment time is also found. The $\mathrm{F} / \mathrm{C}$ ratio for the covered films approaches a value of $2\left(\mathrm{CF}_{2}\right)$, which is significantly higher than the final $\mathrm{F} / \mathrm{C}$ ratio for uncovered films (maximal value 0.9 ).

Analogous to the argon plasma treatment, PAAc films were treated with a $\mathrm{CF}_{4}$ plasma for $1000 \mathrm{~s}$ in between differently spaced glass plates. The effect of varying the distance in between the glass plates on chemical composition of the surface was studied with XPS and the results are given in Figure 9. The $\mathrm{O} / \mathrm{C}$ ratio reaches a plateau at distances of more than $1.5 \mathrm{~mm}$. The $\mathrm{F} / \mathrm{C}$ ratio also reaches a plateau at distances of more than $2 \mathrm{~mm}$. This plateau is significantly higher than the level found for uncovered plasma-treated films. At very small distances between the plates ( $\leq 0.5 \mathrm{~mm}$ ), the chemical composition of the modified films approaches that of unmodified films.

The results of the AD-XPS measurements on PAAc films treated with a $\mathrm{CF}_{4}$ plasma for different time periods are given in Figure 10 . The $\mathrm{F} / \mathrm{C}$ ratio increases with decreasing depth, indicating that the top surface is enriched in fluorine during the plasma treatment. Because of the scatter of the data points, no trends for the $\mathrm{O} / \mathrm{C}$ ratio can be depicted.

\section{OES During Argon and $\mathrm{CF}_{4}$ Plasma Treatments}

OES was used to qualitatively study the degradation products of PAAc and PE films during argon or $\mathrm{CF}_{4}$ plasma treatments. Spectra of the argon plasma treatment of PAAc and PE were recorded and these spectra were compared to the emission spectrum of an argon plasma without any film present (spectra not shown). The spectrum of the argon plasma was comparable to the spectrum obtained during the argon plasma treatment of $\mathrm{PE}$, except for a small difference in peak height at $384 \mathrm{~nm}$. When the spectrum obtained during the argon plasma treatment of PAAc was compared with that of an argon plasma, some distinct differences were observed: First, the absolute intensity of peaks due to excited argon species decreased. Furthermore, some small new peaks appeared in the emission spectrum obtained during the argon plasma treatment of PAAc. 


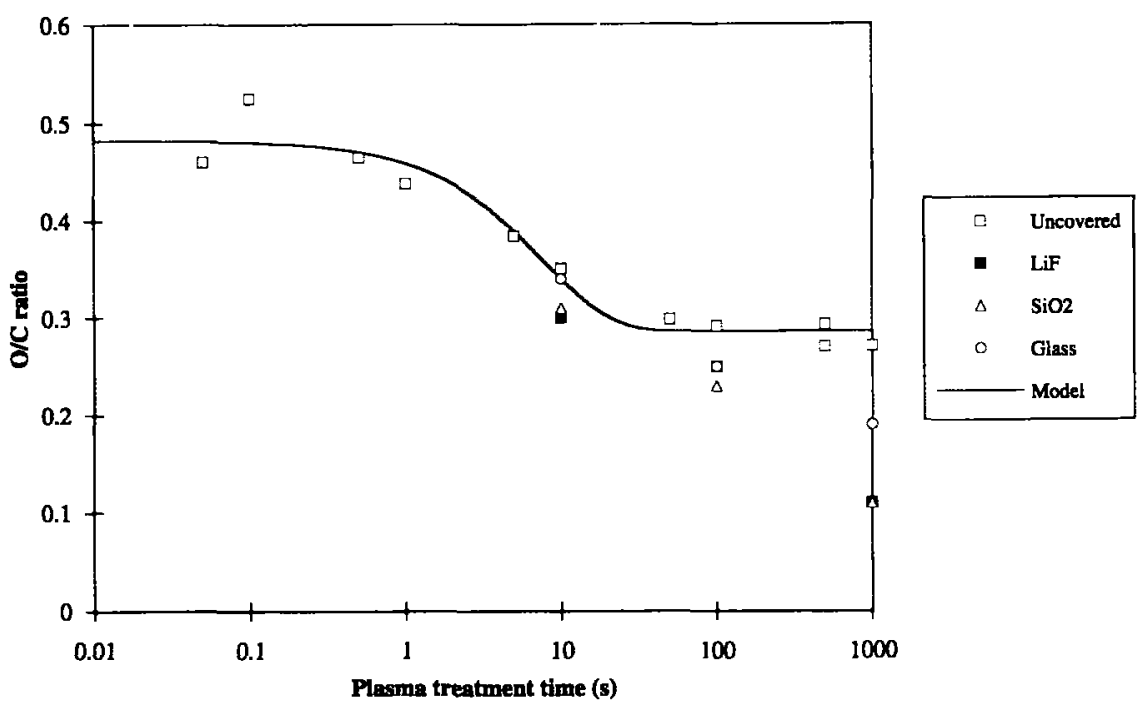

Figure 7 XPS analysis of $\mathrm{CF}_{4}$ plasma-treated PAAc films. The ratio of oxygen to carbon is given as a function of the plasma treatment time. The films were either covered (with glass, $\mathrm{SiO}_{2}$, or $\mathrm{LiF}$ ) during the plasma treatment or not covered. Also, the best fit for eq. (10) is given for plasma-treated (not covered) PAAc films.

To amplify the emission lines of (possible) degradation products with respect to the argon background, a different set of plasma conditions was used. The power input was kept constant, but the residence time of the argon gas was increased by a factor 11 using a lower gas flow and a higher pressure. To investigate which species cause the differences between the emission spectra of an argon plasma and of an argon plasma treatment of PAAc, spectra of argon/carbon dioxide $\left(\mathrm{Ar} / \mathrm{CO}_{2}\right)$ and argon/water $\left(\mathrm{Ar} / \mathrm{H}_{2} \mathrm{O}\right)$ mixtures have been recorded. The emission spectra obtained for argon, $\mathrm{Ar} / \mathrm{CO}_{2}$, and $\mathrm{Ar} /$ $\mathrm{H}_{2} \mathrm{O}$ discharges and spectra obtained during the plasma treatment of PAAc using the second set of plasma conditions are given in Figure 11. The emission spectrum obtained during the argon plasma treatment of $\mathrm{PE}$ was again very similar to that of a pure argon discharge (spectrum not given). Adding

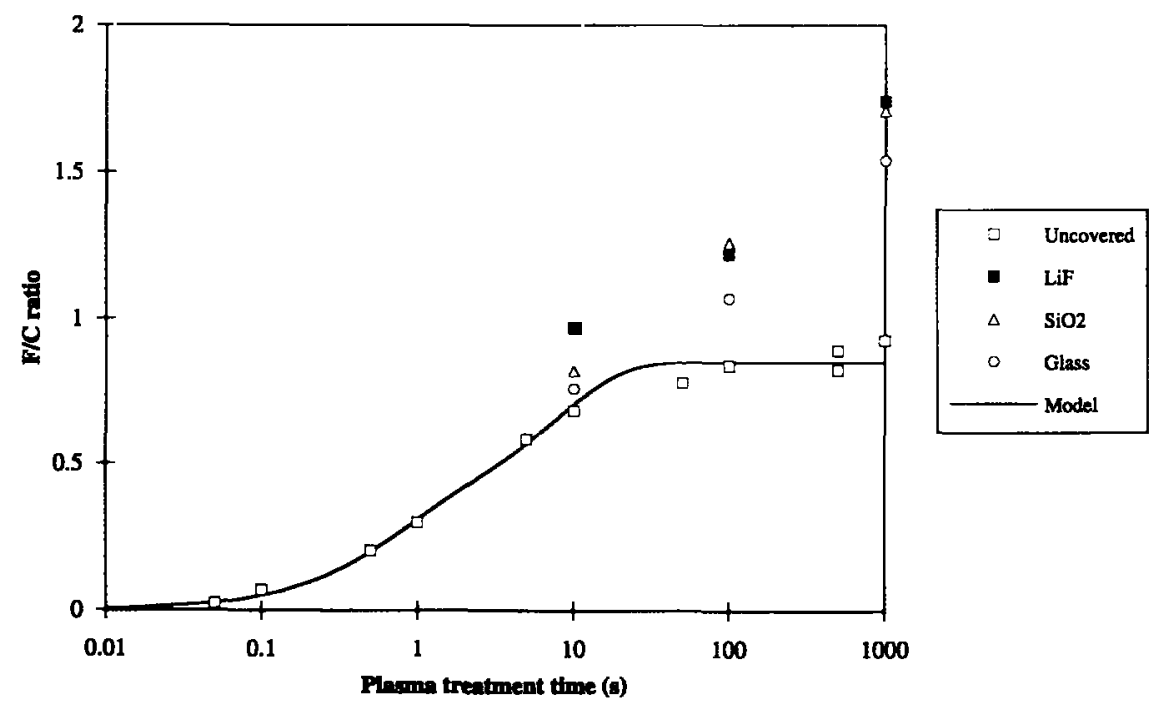

Figure 8 XPS analysis of $\mathrm{CF}_{4}$ plasma-treated PAAc films. The ratio of fluorine to carbon is given as a function of the plasma treatment time. The films were either covered (with glass, $\mathrm{SiO}_{2}$, or LiF) during the plasma treatment or not covered. The best fit for eq. (14) is given for plasma-treated (not covered) PAAc films. 


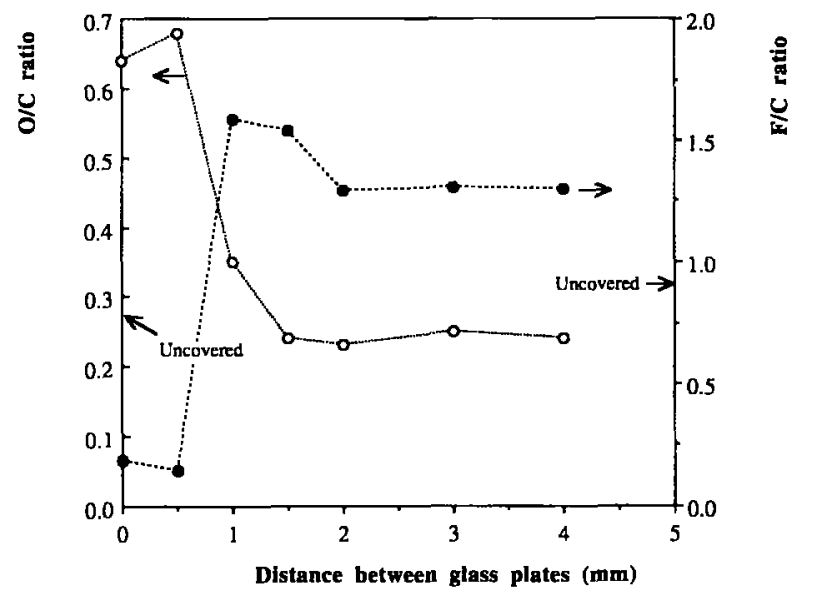

Figure 9 XPS analysis of $\mathrm{CF}_{4}$ plasma-treated PAAc films $(1000 \mathrm{~s})$, which were placed in between two glass plates during the plasma treatment. The oxygen-to-carbon ratios and fluorine-to-carbon ratios are given as a function of the spacing between the glass plates.

small amounts of water or carbon dioxide to argon changes the spectrum drastically. From Figure 11 it can be seen that the absolute emission intensity for these mixtures has decreased significantly. Furthermore, in the $\mathrm{Ar} / \mathrm{H}_{2} \mathrm{O}$ spectrum, two distinct new lines at 486 and $656 \mathrm{~nm}$ are found. The $\mathrm{Ar} / \mathrm{CO}_{2}$ spectrum is completely different from the Ar emission spectrum. Also, a synthesis spectrum, which is a linear combination of the emission spectra of $\mathrm{Ar} /$ $\mathrm{CO}_{2}$ and $\mathrm{Ar} / \mathrm{H}_{2} \mathrm{O}$ discharges, is given. A remarkable similarity between the synthesis spectrum and the spectrum obtained during the argon plasma treatment of PAAc is observed.

OES has also been used to study the degradation products during the $\mathrm{CF}_{4}$ plasma treatment of $\mathrm{PE}$ and PAAc. The emission spectra of $\mathrm{CF}_{4} / \mathrm{H}_{2} \mathrm{O}$ and $\mathrm{CF}_{4} / \mathrm{CO}_{2}$ have also been recorded (data not shown). Even when large amounts of $\mathrm{CO}_{2}$ or water were added to the $\mathrm{CF}_{4}$ gas flow, the emission spectrum did not change. Therefore, it was concluded that in the case of a $\mathrm{CF}_{4}$ plasma treatment of PAAc films OES with a resolution of $2 \mathrm{~nm}$ was not sensitive enough to study the degradation products in the plasma phase.

\section{DISCUSSION}

\section{Argon Plasma Treatment of PAAc}

Treating PAAc films with an argon plasma results in decarboxylation of the PAAc surface. This is concluded from the results given in Figures 1-3. With increasing plasma treatment time, an increasing amount of carboxylic acid groups is lost from the surface, which correlates directly with the decrease in the $\mathrm{O} / \mathrm{C}$ ratio. This is in agreement with the results of Hook et al., who reported that films of poly (methyl methacrylate) ${ }^{25}$ and films of poly (methyl methacrylate-co-methacrylic acid) ${ }^{26}$ were reduced/decarboxylated during argon/water plasma treatments.

By placing a crystal or glass on the polymer film, an attempt was made to prevent a bombardment of reactive species-except the UV radiation-from the plasma phase to the polymer surface. Because a small gap between the cover material and the polymer film will exist, which would still be accessible to reactive species from the plasma phase, a small
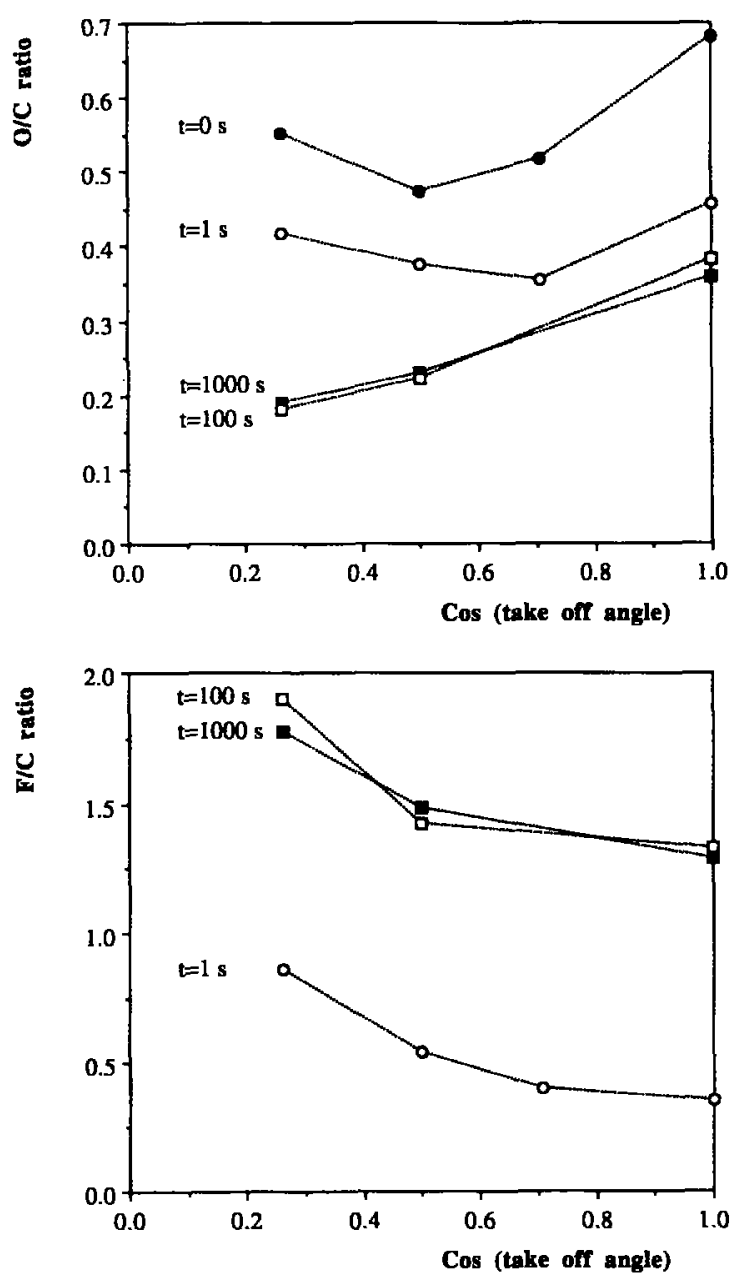

Figure 10 Angle-dependent XPS measurements on $\mathrm{CF}_{4}$ plasma-treated PAAc films. The oxygen-to-carbon ratio (a) and the fluorine-to-carbon ratio (b) are given as a function of the take-off angle for films plasma-treated for varying times. 

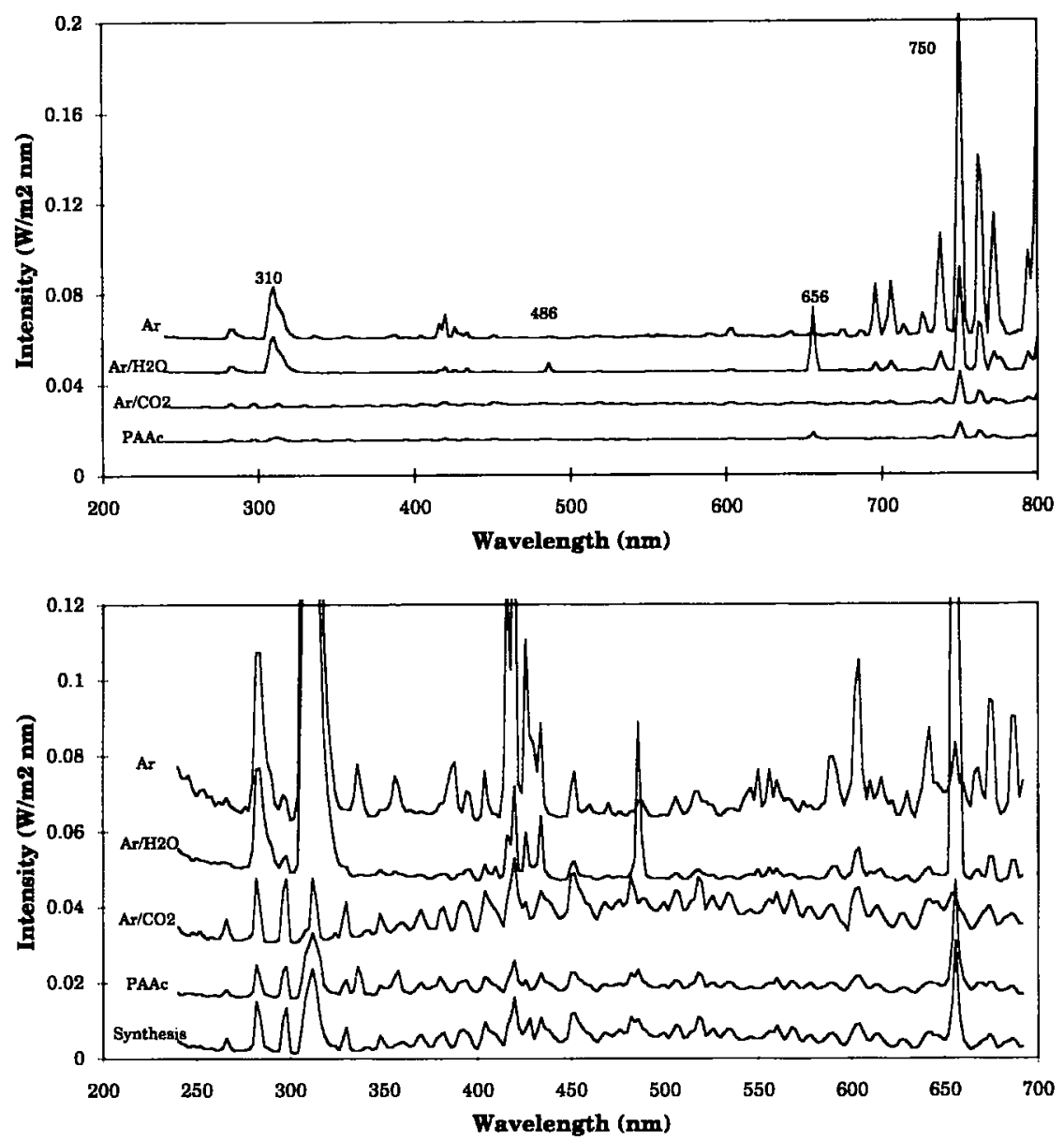

Figure 11 Optical emission spectra (OES) of an argon (Ar) plasma, an argon/carbon dioxide $\left(\mathrm{Ar} / \mathrm{CO}_{2}\right)$ plasma, an argon/water $\left(\mathrm{Ar} / \mathrm{H}_{2} \mathrm{O}\right)$ plasma, and an argon plasma during the treatment of a PAAc film (PAAc). Overview spectra are given in (a) and enlarged (enlargement factor 10) spectra are shown in (b). In (b), a synthesis spectrum consisting of a linear combination of the $\mathrm{Ar} / \mathrm{H}_{2} \mathrm{O}$ and the $\mathrm{Ar} / \mathrm{CO}_{2}$ spectrum is also presented. Discharge conditions: $44 \mathrm{~W}, 0.24 \mathrm{mbar}$; gas flows: $\mathrm{Ar}$ ( $3 \mathrm{sccm} / \mathrm{min}) ; \mathrm{Ar} / \mathrm{H}_{2} \mathrm{O}$ (3 sccm $/ \mathrm{min} \mathrm{Ar}+0.3$ $\left.\mathrm{sccm} / \mathrm{min} \mathrm{H}_{2} \mathrm{O}\right) ; \mathrm{Ar} / \mathrm{CO}_{2}\left(3 \mathrm{sccm} / \mathrm{min} \mathrm{Ar}+0.3 \mathrm{sccm} / \mathrm{min} \mathrm{CO}_{2}\right) ; \mathrm{PAAc}$, plasma treatment of $90 \mathrm{~cm}^{2}$ PAAc ( $3 \mathrm{sccm} / \mathrm{min}$ Ar). The synthesis spectrum is a combination of the following spectra: $0.075 * \mathrm{Ar} / \mathrm{H}_{2} \mathrm{O}+0.55 * \mathrm{Ar} / \mathrm{H}_{2} \mathrm{O}$. For clarity, offsets are used for the different spectra.

flux of reactive species from the plasma phase might still reach the surface. To investigate this effect, the gap size between the surface of the substrate and the cover material was deliberately increased. From Figure 4 it can be seen that a flux of reactive species from the argon plasma phase does not influence the surface chemistry of the PAAc film.

Although no changes in the surface chemistry are observed for argon plasma-treated PAAc films, which were covered by glass or $\mathrm{SiO}_{2}$ during the plasma treatment, decarboxylation of the LiF-covered PAAc surface is found. This decarboxylation is caused by UV transmitted by the LiF crystal (wavelength >104 $\mathrm{nm}$ ). Because the emission spec- trum of the argon plasma consists mainly of lines originating from excited argon atoms ${ }^{27}$ and not from ionized argon atoms ${ }^{28}$ ( see also Fig. 11), it seems likely that the decarboxylation of PAAc is caused by UV radiation of $104.8 \mathrm{~nm}$, which is the predominant line in the vacuum UV spectrum of excited argon.

If the surface modification would be purely photochemical, the PAAc surface would be totally depleted from carboxylic acid groups at long treatment times. For LiF-covered films, this seems possible, but for uncovered films, this is not the case (see Figs. 2 and 3). Therefore, a second process should occur simultaneously. Although the flux of reactive 
species from the plasma phase does not change the surface chemistry directly (see Fig. 4), this second process should still be caused by this flux. Most likely, a bombardment of ions and/or electrons to the surface causes sputtering of the surface. The observed carboxylic acid group levels (and $\mathrm{O} / \mathrm{C}$ ratios) at long treatment times are caused by a balance between the sputtering-a surface renewal-and a decarboxylation process. Explaining the surface modification by an argon plasma in terms of a combined photochemical and particle-induced process is in agreement with the model proposed by Clark and Dilks for the argon plasma modification of fluorinated polymer surfaces. ${ }^{29}$

From the AD-XPS measurements for argon plasma-treated films, given in Figure 5, it can be seen that the decarboxylation takes place homogeneously over the probed depth. This is concluded from the fact that the $\mathrm{O} / \mathrm{C}$ ratio of plasma-treated films is nearly independent of the take-off angle. The photochemical decarboxylation occurs, thus, over a depth much larger than the XPS analysis depth ( $100 \AA$ ). For not-plasma-treated PAAc films, there seems to be a tendency to have an enrichment of oxygen in deeper surface layers. This is probably caused by a thin hydrocarbon overlayer of an unknown origin on the surface of the PAAc films. The presence of this layer would explain the deviation of the $\mathrm{O} / \mathrm{C}$ ratio and the fraction of carboxylic acid groups found for pure PAAc films from the theoretically expected values of respectively 0.67 and 0.33 .

OES has been used to qualitatively study the plasma phase during the argon plasma treatment of PAAc. Because of the complexity of the spectra and of the numerous cooperative and counteractive processes between different (excited) species in the plasma, we have used OES only as a qualitative method to detect degradation products in the plasma phase. From the emission spectrum of an argon plasma, it can be seen that the spectra consist mainly of peaks originating from excited argon atoms. ${ }^{27}$ During the argon plasma treatment of PAAc films, some new peaks are found, which seem to be caused by hydrogen ( 486 and $656 \mathrm{~nm}$, atomic hydrogen lines $\left.{ }^{27,28}\right)$, possibly water ${ }^{30}(306-309 \mathrm{~nm})$, and carbon dioxide fragments. ${ }^{30,31}$ The synthesis spectrum [given in Fig. 11(b)], which is a linear combination of the $\mathrm{Ar} / \mathrm{CO}_{2}$ and $\mathrm{Ar} / \mathrm{H}_{2} \mathrm{O}$ spectrum, is similar to the spectrum obtained during the argon plasma treatment of PAAc. The few differences between these spectra-peaks at 336 and $358 \mathrm{~nm}$-are probably due to a very small air leak during the plasma treatment of PAAc. Based on these results, it is con- cluded that during the plasma treatment of PAAc, $\mathrm{H}_{2} \mathrm{O}$ and $\mathrm{CO}_{2}$ are liberated from the surface. Furthermore, it seems possible that also a small amount of hydrogen is formed during the argon plasma treatment. Most likely, the $\mathrm{CO}_{2}$ originates from carboxylic acid groups, which are decomposed during the plasma treatment. The liberated $\mathrm{H}_{2} \mathrm{O}$ may be due to tightly bound water in the polymer or may be formed during the discharge.

\section{$\mathrm{CF}_{4}$ Plasma Treatment of PAAC}

The results of the XPS analysis of $\mathrm{CF}_{4}$ plasmatreated films, given in Figures 6-10, show that PAAc films are decarboxylated and fluorinated during a $\mathrm{CF}_{4}$ plasma treatment. Furthermore, from Figures $6-8$, it can be seen that regardless of the type of material used to cover the PAAc film during the plasma treatment the PAAc surfaces are fluorinated and decarboxylated. The differences in surface chemistry among $\mathrm{LiF}, \mathrm{SiO}_{2}$, and glass-covered films after a $\mathrm{CF}_{4}$ plasma treatment are small. This indicates that, in contrast to the argon plasma treatment, the contribution of the photochemically induced decarboxylation of PAAc to the surface chemistry is insignificant. The surface modification is thus dominated by a reaction of active species from the plasma phase.

During the $\mathrm{CF}_{4}$ plasma treatment of different polymers, fluorine-containing groups, such as $\mathrm{CF}$, $\mathrm{CF}_{2}$, and $\mathrm{CF}_{3}$, are introduced at the surface. ${ }^{32-34}$ From the spectra of PAAc films treated for different time periods, it is clear that the surface is progressively fluorinated. With increasing plasma treatment time, higher fluorinated groups are formed. It seems likely that abundantly present atomic fluorine ${ }^{35}$ causes the observed fluorination ${ }^{9}$ and decarboxylation. In contrast to the UV-induced decarboxylation, the decarboxylation / fluorination by reactive species from the plasma phase seems to be bound to the outermost surface (see Fig. 10).

Because the $\mathrm{O} / \mathrm{C}$ ratio levels off at long plasma treatment times, a second process counteractive to the fluorination/decarboxylation by species from the $\mathrm{CF}_{4}$ plasma phase occurs. This second process is most likely a combined sputter and chemicaletching process. The surface chemistry observed for $\mathrm{CF}_{4}$ plasma-treated PAAc films is thus the result of a fluorination/decarboxylation and sputter/etching process. When a PAAc film is covered during the plasma treatment, the balance between these two processes shifts. By decreasing the distance between the covering plates, the etching rates decrease. Therefore, at small distances, the fluorination/de- 


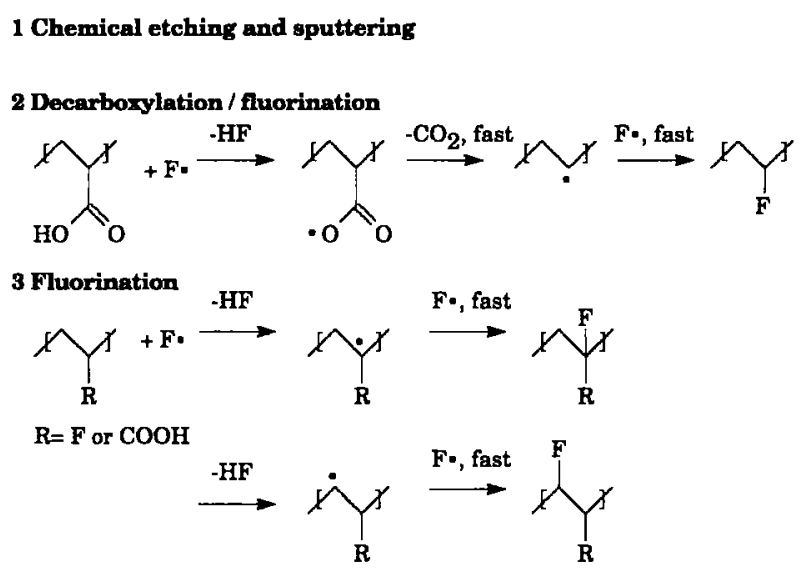

Figure 12 Schematic presentation of the processes occurring at the surface of a PAAc film during a $\mathrm{CF}_{4}$ plasma treatment. For the fluorination reaction ( reaction 3 ), several consecutive fluorination reactions, leading to a totally fluorinated surface, are expected.

carboxylation process dominates, leading to more fluorinated surfaces. This explains the higher fluorination level for covered films and can ultimately lead to completely fluorinated and decarboxylated surfaces. Indeed, PTFE-like surfaces have been obtained for covered PAAc films (see Fig. 6). At very small distances ( $\leq 1 \mathrm{~mm}$ ), the flux of reactive species from the plasma phase is most likely too small to have reached an equilibrium chemical state at the surface. This explains why at the shortest distances the chemical state of modified PAAc films still resembles the chemical state of unmodified PAAc films.

From Figure 8 it can be seen that the fluorine incorporation on the PAAc surface starts at a treatment time of approximately $0.1 \mathrm{~s}$ and that the decarboxylation starts at a treatment time of $1 \mathrm{~s}$ ( see Fig. 7). Therefore, although the fluorination and decarboxylation seem to be related, an additional fluorination process of the surface occurs. A schematic presentation of the processes occurring at the PAAc surface during a $\mathrm{CF}_{4}$ plasma treatment is given in Figure 12.

\section{Kinetics of the Argon Plasma Treatment of PAAC}

The chemical composition of the surface of PAAc films during an argon plasma treatment is dominated by two processes: The surface is photochemically decarboxylated by vacuum UV radiation and is simultaneously etched by species (presumably ions and/or electrons) from the plasma phase. These processes can be used to derive a kinetic expression for the argon plasma treatment of PAAc.
The rate of the photochemical process is proportional to the flux of absorbed photons $(I)$ and to a photochemical reaction rate constant $(k) .^{36}$ Furthermore, the rate of the sputtering process is determined by the particle flux to the surface and a sputtering constant. If it is assumed that the particle flux to the surface is constant, the sputter rate $(b)$ is constant. The change of the concentration of carboxylic acid groups on the surface $(d[\mathrm{COOH}] / d t)$ can thus be described by the following kinetic equation:

$$
\frac{d[\mathrm{COOH}]}{d t}=-k I+b
$$

It should be noted that the sputtering process is actually a surface renewal process, and, therefore, the constant $b$ in eq. ( 1 ) should be positive. The fraction of photons absorbed by a certain depth $(d)$ from the surface can be described by the Lambert-Beer law:

$$
I=I_{0}\left(1-e^{-a_{0} d[\mathrm{COOH}]}\right)
$$

The absorption constant is denoted by $a_{0}$. If one assumes that the photons are weakly absorbed $\left(a_{0} d[\mathrm{COOH}] \ll 1\right)$, eq. ( 2$)$ can be simplified using the Taylor expression to

$$
I \approx I_{0} a_{0} d[\mathrm{COOH}]
$$

Combining eqs. (1) and (3) gives

$$
\begin{aligned}
\frac{d[\mathrm{COOH}]}{d t}=-k I_{0} a_{0} d[\mathrm{COOH}] & +b \\
& =-z[\mathrm{COOH}]+b
\end{aligned}
$$

The change in concentration of carboxylic acid groups is thus a combination of a zero-order surface renewal and a first-order photochemical process. Solving eq. (4) using an initial concentration $[\mathrm{COOH}]_{0}$ at $t=0 \mathrm{~s}$ yields

$$
[\mathrm{COOH}]=\left([\mathrm{COOH}]_{0}-\frac{b}{z}\right) e^{-z t}+\frac{b}{z}
$$

Some remarks considering une use of eq. (5) for the kinetic description of the argon plasma treatment of PAAc films should be made: In deriving eq. (2), we have assumed that the attenuation of the incident photon flux over the probed depth is small. The depth probed by XPS is typically $100 \AA$. The validity of using the Taylor expression in eq. (2) can be checked by using the absorption constant calculated 
by Clark and Dilks ${ }^{29}$ for the absorption of UV radiation of $130 \mathrm{~nm}$ in polyethylene $\left(a_{0}[\mathrm{C}]=2.10^{7}\right.$ $\mathrm{m}^{-1}$ ) to estimate the fraction of absorbed photons. Approximately $18 \%$ is absorbed in the top $100 \AA$. Although the absolute values of the absorption constants vary ${ }^{37}$ and are strongly dependent on the wavelength of the UV and the polymer used, it seems that the assumption $\left(a_{0} d[\mathrm{C}] \ll 1\right)$ is not unreasonable.

Furthermore, XPS data have been used to fit eq. (5). In the calculations that are used to translate the measured peak areas into atom percentages, the corrected (corrected for its cross section) area of one peak is normalized to the sum of all corrected peak areas. Thus, a decrease in the amount of oxygen, which corresponds to a smaller peak area of the $01 s$ peak, will affect both the nominator and the denominator in the calculation. The actual decrease in concentration will be larger than is indicated by the atom percentage of oxygen. Therefore, a better indication of the actual concentration will be obtained if a normalization to an independent reference element is made. For the PAAc films, carbon seems to be most suitable. Therefore, the $\mathrm{O} / \mathrm{C}$ ratios are used to fit eq. (5). The total amount of carbon probed may vary somewhat for PAAc films treated with an argon plasma for different time periods. Due to the decarboxylation, some carbon will be lost during the plasma treatment. This effect is counteracted by the fact that XPS probes a larger depth of a polymer with a lower density. Finally, it should be noted that XPS can only yield relative elemental concentrations, in contrast to the absolute concentrations needed in eq. (5).

The sensitivity of XPS decreases for layers deeper under the outermost surface. To obtain correct relative concentrations, the film should be homogeneous over the depth probed. For argon plasmatreated PAAc films, the layer probed by XPS was indeed homogeneous according to the AD-XPS measurements (see Fig. 5).

Equation (5) has been used to fit the fraction of carboxylic acid groups left on the surface as well as the $0 / C$ ratios as a function of the treatment time. The best fits (shown in Figs. 2 and 3) describe the experimental data well over the whole range of plasma treatment times (more than four orders of magnitude). The values for the fitting parameters are given in Table I. The starting concentrations $\left([\mathrm{COOH}]_{0}\right.$ and $\left.(\mathrm{O} / \mathrm{C})_{0}\right)$ of not-plasma-treated films determined by fitting eq. (5) are in good agreement with the experimentally measured values. At long plasma treatment times, the term $e^{-z t}$ becomes extremely small and the final concentration is determined by the $b / z$ ratio. In fitting eq. (5), actually only 1 degree of freedom (variable $z$ ) is left. Within

Table I Kinetics of the Argon and $\mathrm{CF}_{4}$ Plasma Treatment of PAAc

\begin{tabular}{|c|c|c|c|c|c|c|}
\hline \multicolumn{7}{|c|}{ Argon Plasma Treatment of PAAc } \\
\hline $\begin{array}{l}\text { Parameter } \\
\text { Fitted }\end{array}$ & Equation & Start Conc & $z^{\mathrm{a}}$ & $b$ & $b / z$ & Correlation \\
\hline 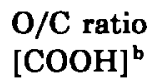 & $\begin{array}{l}(5) \\
(5)\end{array}$ & $\begin{array}{l}0.511 \\
0.243\end{array}$ & $\begin{array}{l}0.10 \\
0.08\end{array}$ & $\begin{array}{l}0.019 \\
0.0066\end{array}$ & $\begin{array}{l}0.194 \\
0.080\end{array}$ & $\begin{array}{l}0.998 \\
0.997\end{array}$ \\
\hline \multicolumn{7}{|c|}{$\mathrm{CF}_{4}$ Plasma Treatment of PAAc } \\
\hline $\begin{array}{c}\text { Parameter } \\
\text { Fitted }\end{array}$ & Equation & Start Conc & $k_{1}{ }^{a}$ & $R$ & $R / k_{1}$ & Correlation \\
\hline \multirow[t]{2}{*}{$\mathrm{O} / \mathrm{C}$} & (10) & 0.483 & 0.13 & 0.037 & 0.286 & 0.998 \\
\hline & & $k_{1}{ }^{\mathrm{c}}$ & $k_{2}^{\mathrm{d}}$ & $p$ & $q$ & \\
\hline $\mathrm{F} / \mathrm{C}$ & (14) & 0.13 & 1.7 & 0.85 & -0.54 & 0.997 \\
\hline
\end{tabular}

The experimental data obtained from XPS measurements have been fitted with eq. (5), (10), or (14). A quasi-Newtonian fitting procedure has been used to obtain the best fit.

- Changing this value with \pm 0.02 does not significantly influence the fit.

t The fraction of carboxylic acid groups left on the surface, obtained by peak fitting the C1s spectra of argon plasma-treated PAAc films, was used for fitting.

The reaction constant $k_{1}$, obtained via fitting eq. (10), was transferred to eq. (14).

Changing this value with 0.5 does not significantly influence the fit; the variation of the $q$ value is then \pm 0.05 . 
the accuracy of the experimental data, the value for $z$ is equal for the fit of the [COOH] and for the fit of the $0 / C$ ratio. Because XPS data are used for the fitting of eq. (5), the absolute values of the constants obtained are hard to interpret quantitatively, but they should still be useful for the comparison of different plasma conditions.

Although the described model fits well to the experimental data, two effects are not covered in this model: First, it is assumed that the etching/sputtering is a zero-order process, which is primarily determined by the bombardment of species from the plasma phase. It seems possible that the etching rate may also be dependent on the surface chemistry and that this rate may thus change during the plasma treatment process. Furthermore, at long treatment times, a substantial layer beneath the surface will be decarboxylated by the vacuum UV radiation. The etching process, which renews the surface, will therefore bring less oxygen rich "bulk" material to the surface. This might gradually lower the steadystate carboxylic acid concentration on the surface.

\section{Kinetics of the $\mathrm{CF}_{4}$ Plasma Treatment of PAAc}

During a $\mathrm{CF}_{4}$ plasma treatment of PAAc, the surface chemistry is modified by a bombardment of reactive species-presumably atomic fluorine-from the plasma phase. The chemical processes occurring at the surface can be divided into a combined sputter and chemical-etching process, a combined decarboxylation/fluorination, and a fluorination process (see Fig. 12). The etching rate is primarily dependent on the bombardment rate from species from the plasma phase. In analogy to the argon plasma treatment, this would yield a zero-order reaction (with a rate constant $R$ ). For the combined decarboxylation/fluorination process and for the fluorination process, the first reaction step, hydrogen abstraction, is assumed to be rate-limiting. Furthermore, it seems likely that the bombardment rate of reactive species to the surface, which cause the hydrogen abstraction, is constant. This rate can thus be incorporated into the reaction-rate constants. The reaction-rate constant for the decarboxylation/ fluorination reaction is given by $k_{1}$ and that for the fluorination reaction by $k_{2}$. The following kinetic expressions for the carboxylic acid ([ $\mathrm{COOH}])$ and fluorine ([F]) concentrations on the surface can thus be derived:

$$
\frac{d[\mathrm{COOH}]}{d t}=R-k_{1}[\mathrm{COOH}]
$$

$$
\frac{d[\mathrm{~F}]}{d t}=-R+k_{1}[\mathrm{COOH}]+k_{2}[\mathrm{H}]
$$

The fluorination reaction is dependent on the hydrogen concentration ([H]). If one assumes that only atomic fluorine is incorporated at the polymer backbone and that the molecular weight remains high enough to neglect end-group effects, the sum $(W)$ of the hydrogen, fluorine, and carboxylic acid group concentration should be constant:

$$
W=[\mathrm{H}]+[\mathrm{F}]+[\mathrm{COOH}]
$$

Combined with eq. (7), this results in

$$
\begin{aligned}
\frac{d[\mathrm{~F}]}{d t}=-R+k_{1}[\mathrm{COOH}] & \\
& +k_{2}(W-[\mathrm{F}]-[\mathrm{COOH}])
\end{aligned}
$$

Solving eq. (6) with a starting carboxylic acid group concentration $\left([\mathrm{COOH}]_{0}\right)$ at $t=0 \mathrm{~s}$ yields

$$
[\mathrm{COOH}]=\left([\mathrm{COOH}]_{0}-\frac{R}{k_{1}}\right) e^{-k_{1} t}+\frac{R}{k_{1}}
$$

Equation (10) is similar to eq. (5). Solving eq. (9) with starting conditions $[F]=0$ at $t=0 \mathrm{~s}$ yields

$$
\begin{aligned}
{[\mathrm{F}]=\left(1-e^{-k_{2} t}\right)\left(\frac{-R}{k_{2}}\right.} & +W \\
& \left.+\left(\frac{k_{1}-k_{2}}{k_{2}}\right)[\mathrm{COOH}]\right)
\end{aligned}
$$

Combining eqs. (10) and (11) results in

$$
\begin{aligned}
{[\mathrm{F}] } & =\left(1-e^{-k_{2} t}\right)\left(\frac{-R}{k_{2}}+W+\left(\frac{k_{1}-k_{2}}{k_{2}}\right)\right. \\
& \left.\times\left([\mathrm{COOH}]_{0}-\frac{R}{k_{1}}\right) e^{-k_{1} t}+\left(\frac{k_{1}-k_{2}}{k_{2}}\right) \frac{R}{k_{1}}\right)
\end{aligned}
$$

Equation (12) can be simplified to

$$
\text { with } \begin{aligned}
p & =\frac{-R}{k_{2}}+W+\left(\frac{k_{1}-k_{2}}{k_{2}}\right) \frac{R}{k_{1}} \text { and } \\
q & =\left(\frac{k_{1}-k_{2}}{k_{2}}\right)\left([\mathrm{COOH}]_{0}-\frac{R}{k_{1}}\right) \\
{[\mathrm{F}] } & =\left(1-e^{-k_{2} t}\right)\left(p+q e^{-k_{1} t}\right)
\end{aligned}
$$


In analogy to eq. (5), only 1 degree of freedom $\left(k_{1}\right)$ is left in eq. (10). This constant can be transferred to eq. (14). Furthermore, at long plasma treatment times, the fluorine concentration in eq. (14) will yield a value $p$. This reduces the degree of freedom in eq. (14) to two parameters $\left(k_{2}\right.$ and $q$ ).

To test whether the reactions induced by the $\mathrm{CF}_{4}$ plasma treatment of PAAc can be described by eqs. (10) and (14), the measured $O / C$ and $F / C$ ratios have been fitted as a function of the plasma treatment time. The $\mathrm{O} / \mathrm{C}$ ratio is used as a relative indication of the concentration of carboxylic acid groups and the $\mathrm{F} / \mathrm{C}$ ratio as a relative indication of the amount of fluorine incorporated. The best fits given in Figures 7 and 8 show that the described model agrees well with the measured data over the whole time range. This agreement is remarkable because only relative concentrations derived from XPS measurements on inhomogeneous films have been fitted. The values of the fit parameters are given in Table I. The reaction constants obtained from fitting eqs. (10) and (14) to the experimental data yield relative numbers that are only suitable for comparison of different plasma conditions. If the fitted rate constants ( $k_{1}$ and $k_{2}$, given in Table I) are used in eq. (7), it can be easily seen that, initially, the fluorination rate due to hydrogen abstraction from the polymer backbone is larger than the fluorination rate due to the decarboxylation reaction.

\section{CONCLUSIONS}

PAAc films are decarboxylated during an argon plasma treatment. This decarboxylation is caused by vacuum UV radiation $(\lambda<150 \mathrm{~nm})$. During a $\mathrm{CF}_{4}$ plasma treatment, the PAAc films are not only fluorinated but also decarboxylated. This is caused by a bombardment of reactive species-presumably atomic fluorine-from the plasma to the PAAc surface. During both types of plasma treatments, etching of the surface occurs. Based on these processes, kinetic equations for both types of plasma treatments have been derived, which can be used to describe the kinetic measurements adequately.

The authors would like to thank Dr. G. Engbers for his valuable contributions during discussions, Mr. A. van den Berg for assisting with the XPS measurements, and Mr. Th. Wilting (Avery \& Fasson, Leiden, The Netherlands) for offering us the possibility to use the spectroradiometer. Furthermore, they are grateful to DSM (Geleen, The Netherlands) for financial support of this research.

\section{REFERENCES}

1. P. W. Rose and E. M. Liston, Plast. Eng., 41, 41 (1985).

2. J. H. Lee, J. W. Park, and H. B. Lee, Biomaterials, 12, 443 (1991).

3. D. L. Cho, P. M. Claesson, C.-G. Gölander, and K. Johansson, J. Appl. Polym. Sci., 41, 1373 (1990).

4. N. Inagaki and M. Matsunaga, Polym. Bull., 13, 349 (1985).

5. G. H. Heider, M. B. Gelbert, and A. M. Yacynych, Anal. Chem., 54, 322 (1982).

6. J. L. Grant, D. S. Dunn, and D. J. McClure, J. Vac. Sci. Technol., A6, 2213 (1988).

7. H. Yasuda, H. C. Marsh, S. Brandt, and C. N. Reilley, J. Polym. Sci. Polym. Chem. Ed., 15, 991 (1977).

8. L. J. Gerenser, J. Adhes. Sci. Tech., 1, 303 (1987).

9. F. D. Egitto, V. Vukanovic, and G. N. Taylor, in Plasma Deposition, Treatment, and Etching of Polymers, R. d'Agostino, Ed. Academic Press, Boston, 1990, Chap. 5.

10. J. Meischer and H.-U. Poll, Acta Polym., 32, 203 (1981).

11. Y.-L. Hsieh and M. Wu, J. Appl. Polym. Sci., 43, 2067 (1991).

12. A. Bruil, J. G. A. Terlingen, T. Beugeling, W. G. van Aken and J. Feijen, Biomaterials, 13, 915 (1992).

13. J. G. A. Terlingen, A. S. Hoffman, and J. Feijen, J. Appl. Polym. Sci., 50, 1529 (1993).

14. J. G. A. Terlingen, J. Feijen, and A. S. Hoffman, J. Colloid Interface Sci., 155, 55 (1993).

15. J. G. A. Terlingen, L. M. Brenneisen, H. T. J. Supèr, A. P. Pijpers, A. S. Hoffman, and J. Feijen, J. Biomater. Sci. Polym. Ed., 4, 165 (1993).

16. D. T. Clark and A. Dilks, J. Polym. Sci. Polym. Chem. Ed., 18, 1233 (1980).

17. M. Hudis and L. E. Prescott, Polym. Lett., 10, 179 (1972).

18. H. Yasuda, J. Macromol. Sci.-Chem., A10, 383 (1976).

19. H. S. Munro, Polym. Mater. Sci. Eng., 56, 318 (1987).

20. A. Gilbert and J. Baggott, Essentials of Molecular Photochemistry, Blackwell, Oxford, 1991.

21. V. M. Donnelly, in Plasma Diagnostics, Vol. 1, Discharge Parameters and Chemistry, $O$. Auciello and D. L. Flamm, Eds., Academic Press, San Diego, 1989, Chap. 1.

22. D. M. Manos and H. F. Dylla, in Plasma Etching, An Introduction, D. M. Manos and D. L. Flamm, Eds., Academic Press, San Diego, 1989, Chap. 4.

23. D. Kiaei, A. S. Hoffman, B. D. Ratner, T. A. Horbett, and L. O. Reynolds, J. Appl. Polym. Sci. Appl. Polym. Symp., 42, 269 (1988).

24. C. D. Wagner, W. M. Riggs, L. E. Davis, and J. F. Moulder, in Handbook of X-ray Photoelectron Spectroscopy, G. E. Muilenberg, Ed., Perkin-Elmer Corp., Eden Prairie, Minnesota, 1979. 
25. T. J. Hook, J. A. Gardella, Jr., and L. Salvati, Jr., J. Mater. Sci., 2, 117 (1987).

26. T. J. Hook, J. A. Gardella, Jr., and L. Salvati, Jr., J. Mater. Sci., 2, 132 (1987).

27. R. C. Weast and M. J. Astle, CRC Handbook of Chemistry and Physics, CRC Press, Boca Raton, FL, 1982.

28. B. Ceccaroli and A. Ricard, Rev. Phys. Appl., 21, 197 (1986).

29. D. T. Clark and A. Dilks, J. Polym. Sci. Polym. Chem. Ed., 15, 2321 (1977).

30. S. Murayama, Bunko Kenkyu, 24, 231 (1975); Chem. Abstr., 85 (2), 13307k (1976).

31. R. d'Agostino, F. Cramarossa, F. Fracassi, and F. Illuzi, in Plasma Deposition, Treatment, and Etching of Polymers, R. d'Agostino, Ed., Academic Press, Boston, 1990, Chap. 2.

32. Y. Momose, H. Nishiyama, M. Noguchi, and S. Susuma, Nippon Kagaku Kaishi, 10, 1876 (1985); Chem. Abstr., 104 (2), 6288n (1985).
33. T. Yasuda, T. Okuno, K. Yoshida, and H. Yasuda, J. Appl. Polym. Sci. Part B Polym. Phys., 26, 1781 (1988).

34. A. Bruil, L. M. Brenneisen, J. G. A. Terlingen, T. Beugeling, W. G. van Aken, and J. Feijen, J. Colloid Interface Sci., in press.

35. T. H. J. Bisschops, PhD Thesis, University of Eindhoven, Eindhoven, The Netherlands, 1987.

36. B. Ranby and J. F. Rabek, in Photodegradation, Photooxidation and Photostabilization of Polymers, Principles and Applications, Wiley, New York, 1975.

37. E. M. Liston, in Congress Proceedings ISPC-7, Eindhoven, July 1985, p. 513.

Received May 14, 1993

Accepted September 3, 1993 